\title{
FACT-CHECKING AND FAKE NEWS VERIFICATION IN THE WAKE OF THE PANDEMIC AND ENSUING INFODEMIC
}

Craig Silverman (ed.): Verification Handbook: For Disinformation and Media Manipulation, European Journalism Centre 2020, 151 pages.

On the 2nd of February 2020, the WHO issued a Novel Coronavirus (2019-nCoV) Situation Report, in which it stated that the outbreak of the new virus had been accompanied by a massive infodemic - "an over-abundance of information - some accurate and some not - that made it hard for people to find trustworthy sources and reliable information when they need it" (WHO 2020). It was in February 2020 , when the world outside of China knew very little about what would later be known as lockdown and just weeks before the public health emergency became the COVID-19 pandemic. The first and the second wave of the coronavirus disease spread rapidly across the globe and were followed by waves of infodemic.

In this overabundance of information, Craig Silverman's latest book serves as a light in the tunnel and a perfect guide for journalists, media researchers and Internet users who want to gain knowledge, acquire skills to verify the news on social media, investigate fake profiles, identify bots and cyborgs, fake apps and deep fakes and other forms of manipulation and disinformation. One could not imagine a better time and more urgent need for such a book to launch.

"Verification Handbook: For Disinformation and Media Manipulation" is the third in the series of excellent books devoted to fact-checking. This handbook was written by journalists and editors from different continents, that replied to an invitation issued by Craig Silverman, an author of groundbreaking works: "Regret the Error: How Media Mistakes Pollute the Press and Imperil Free Speech" (a book published in 2007) and "Lies, Damn Lies, and Viral Content: How News Websites Spread (and Debunk) Online Rumors, Unvaried Claims and Misinformation" (a Tow Centre for Digital journalism, Columbia Journalism School report, published in 2015) both devoted to the consequences of fake news and weak fact-checking.

Craig Silverman's latest book is built on the foundations of the two previous volumes that were both edited and published by Silverman in 2014 and 2015. The first volume, previously available under a title "Verification Handbook: A Definitive 
Guide to Verifying Digital Content for Emergency Coverage" and now titled: "Verification Handbook: An Ultimate Guideline on Digital Age Sourcing for Emergency Coverage" was published in 2014 by European Journalism Centre (EJC) and is a brilliant collection of case studies written by journalists and editors working for news media outlets (such as BBC, CNN, NBC) who described the step-by-step process of verifying videos, photographs and user generated content.

Similar issues are discussed in-depth by different authors in the second handbook edited by C. Silverman and published in 2015 under a title: "Verification Handbook for Investigative Reporting: A Guide to Online Search and Research Techniques for Using UGC and Open-Source Information in Investigations". Both books are excellent sources of inspiration for journalists worldwide. The third volume in the series, reviewed here, includes chapters devoted to recent technological developments, such as bots, cyborgs, deep fakes and many other misguiding practices of fake content creators. Some of the case studies presented in the latest edition of the verification handbook are based on the assumption that readers have a general knowledge about fake news, laid out in the previous publications, which I highly recommend, especially the chapters mentioned in the paragraphs that follow.

"Verification Handbook: An Ultimate Guideline on Digital Age Sourcing for Emergency Coverage" (Silverman 2014) is an excellent resource for journalists dealing with all types of user generated content, described in detail by experienced editors and reporters. For example, Trushar Barot, editor at the Social Media and UGC hub at BBC News, writes about verifying images. This chapter is followed by two case studies in which Philippa Law and Caroline Bannock, editors of the Guardian's open journalism platform, describe how they verified a photo of "a bizarre beach ball during a storm" on the street of London, and Tom Phillips writes about "suspicious street sharks" during Hurricane Sandy. Not wanting to turn this review into a spoiler, I encourage readers to check the verification handbook, filled with posts, tweets and photos that brilliantly illustrate the points highlighted by the authors. In the same volume Madeleine Blaire from the Washington Post writes about assessing and minimizing risks when using UGC, and Gavin Rees from Dart Center for Journalism and Trauma shares his tips on coping with traumatic images. Online tools listed in the last chapter of the handbook provide excellent resources and search engines to identify people, places and verify the authenticity of videos or photographs posted on social media sites.

The second handbook (Silverman 2015) devoted to investigative reporting contains a remarkable chapter written by Claire Wardle, research director at the Tow Center for Digital Journalism at Columbia University, who shares her views on ethical usage of the content provided by someone who has just experienced a traumatic or shocking event. The chapter reflects on the "content that emerged during the Paris shootings in early 2015, and the people who found themselves and their material unexpectedly at the center of the news coverage" (Wardle 2015, p. 56). I couldn't recommend that paper enough.

Frankly, I have no words to recommend the series as much as it ought to be recommended. Craig Silverman's unique 3-part series of "Verification Handbooks" is a must 
read for journalists, editors, citizen reporters, media researchers and scholars, as well as journalism school students or academics interested in social networking platforms.

The third book, published recently, offers insight into newly emerging manipulation technologies, such as deep fakes, discussed in a splendid chapter by Sam Gregory, or bots and cyborgs spotted by Johana Wild and Charlotte Godart from Bellingcat that describe different types of inauthentic activity in attempt to draw the reader's attention to suspicious tweet patterns or stolen profile pictures, as well as automatic generated usernames. CNN reporter Donnie O'Sullivan presents a case study titled "How We Proved That the Biggest Black Lives Matter Page on Facebook Was Fake" and Brandy Zadrozny, an investigative reporter for NBC News, explores fake social media accounts. She remarks: "It's an incredible time to be a journalist; people increasingly live their lives online and tools to find and search a subject's social proles are ubiquitous. At the same time, both normal folks and bad actors are getting smarter about hiding their tracks" (Zadrozny 2020, p. 17). Following digital breadcrumbs is much easier when we have the tools to verify photos, videos, posts, tweets, and various forms of online activities that might lead to disinformation.

The authors of the handbook deal with a wide range of problems, described in the following chapters devoted to the lifecycle of media manipulation; investigating social media accounts; monitoring for fakes and information operations during breaking news; verifying images; deepfakes and emerging manipulation technologies; monitoring and reporting inside closed groups and messaging apps; analyzing ads on social networks, and many more. In this short review I have mentioned only a few of a number of interesting case studies that can teach the readers the vital skills required in today's media environment, especially during the upcoming waves of infodemic.

It's indisputable what Craig Silverman wrote about trust in this day and age:

Trust is (...) key to human connection and relationships. But it's dangerous to operate with default trust in our digital environment. If your default is to trust that the Twitter accounts retweeting a video are all amplifying it organically, you will get gamed. If you trust that the reviews on a product are all from real customers, you'll waste your money. If you trust that every news article in your news feed represent an unbiased collection of what you most need to see, you will end up misinformed. This reality is important for every person to recognize, but it's essential for journalists (Silverman 2020, p. 4).

Equally essential are the tools and skills provided by the authors of the verification handbooks. This is essential for journalists, citizen reporters, journalism students, professionals, volunteers, social media users, content creators, researchers and academics. These three books that were published in 2014, 2015 and 2020, each devoted to different aspects of misinformation and fact-checking, are available at datajournalism.com website. I encourage the readers to translate the handbooks into other languages to make this valuable content accessible to everyone who is not media savvy and to make it easier for people to find trustworthy sources and reliable guidance when they need it (rephrasing the WHO report). 


\section{Bibliography}

Silverman C. (2007). Regret the Error: How Media Mistakes Pollute the Press and Imperil Free Speech. New York.

Silverman C. (ed.). (2014). Verification Handbook: An Ultimate Guideline on Digital Age Sourcing for Emergency Coverage. European Journalism Centre.

Silverman C. (ed.). (2015). Verification Handbook for Investigative Reporting: A Guide to Online Search and Research Techniques for Using UGC and Open Source Information in Investigations. European Journalism Centre.

Silverman C. (2015). Lies, Damn Lies, and Viral Content: How News Websites Spread (and Debunk) Online Rumors, Unveried Claims and Misinformation. A Tow Centre for Digital Journalism, Columbia Journalism School report, published in 2015 [https://towcenter.columbia. edu/news/lies-damn-lies-and-viral-content-how-news-websites-spread-and-debunk-onlinerumors-unverified; 31.01.21].

Silverman C. (ed.). (2020). Verification Handbook: For Disinformation and Media Manipulation. European Journalism Centre.

Wardle C. (2015). Presenting UGC in investigative reporting. In: C. Silverman (ed.). Verification Handbook for Investigative Reporting: A Guide to Online Search and Research Techniques for Using UGC and Open Source Information in Investigations (p. 54-60). European Journalism Centre.

WHO (2020). Novel Coronavirus (2019-nCoV) Situation Report, 2.02.2020 [https://apps.who. int/iris/bitstream/handle/10665/330778/nCoVsitrep02Feb2020-eng.pdf?sequence=1\&isAllowed=y; 30.01.21].

Zadrozny B. (2020). Investigating Social Media Accounts. In: C. Silverman (ed.). Verification Handbook: For Disinformation and Media Manipulation (p. 17-31). European Journalism Centre.

Magdalena Hodalska

(iD) orcid.org/0000-0001-9620-5913 